\title{
Putting Sustainable Consumption into Practice
}

\author{
Ulf Schrader • John Thogersen
}

Received: 3 January 2011 /Accepted: 4 January 2011 /Published online: 8 February 2011

(C) Springer Science+Business Media, LLC. 2011

Private consumption is increasingly blamed for environmental degradation and resource depletion (e.g., European Environment Agency 2005; Gardner et al. 2004). Affluent consumers' choices are also seen as the root cause of unfair conditions for producers and production workers in developing countries, including child labour, unhealthy working conditions and unfair terms of trade (Micheletti and Follesdal 2007). On this background, it has been suggested that, in modern societies, it is neither possible nor ethically justifiable to pursue the traditional model of consumer sovereignty, focussing on individual utility maximization only. Consumers have at least co-responsibility for the consequences of their choices (e.g., Hansen and Schrader 1997). Others warn that policy makers and corporations often stretch the attribution of responsibility to consumers too far, given individual consumers' limited ability to influence pollution, resource use, labour conditions, etc. (e.g., Thøgersen 2005). In such cases, policymakers risk producing consumer helplessness, denial and reaction, and their procrastination results in lost momentum in terms of effectively dealing with the serious problems that we face.

Along these and similar lines of argumentation, much has been said on the necessity and the constraints of sustainable consumption since its prominent consideration in the Agenda 21 at the Rio Conference in 1992. Indeed, sustainable consumption has attracted the attention of scholars from many different disciplines worldwide. Early publications on this topic focussed mainly on the significance of private consumption for sustainable development and on the clarification of sustainable consumption as a new concept (e.g., Hansen and Schrader 1997; Heiskanen and Pantzar 1997; Spaargaren 2003; Spangenberg and Lorek 2002). More recently, the volume and diversity of research on this topic has expanded rapidly, as reflected, among other things, in a large number of special issues on

\footnotetext{
U. Schrader

Division of Economic Education and Sustainable Consumption, Technische Universität Berlin, IBBA, Franklinstr. 28/29, 10587 Berlin, Germany

e-mail: schrader@tu-berlin.de

J. Thøgersen $(\bowtie)$

Department of Marketing, Aarhus School of Business and Social Sciences, Aarhus University,

Haslegaardsvej 10, 8210 Aarhus, Denmark

e-mail: jbt@asb.dk
} 
sustainable consumption. Notable examples, just within the last year, include a special issue of the Journal of Consumer Behaviour on "Sustainability Through Anti-Consumption" edited by Iain Black (November/December 2010), a special issue of the Journal of Macromarketing on "Facing the Challenge of Sustainability in a Changing World" edited by William E. Kilbourne (June 2010) and special issues of the Journal of Industrial Ecology and Natural Resources Forum on "Sustainable Consumption and Production," the former edited by Arnold Tukker, Maurie J. Cohen, Klaus Hubacek, and Oksana Mont (January/February 2010) and the latter by David Le Blanc (February 2010).

On the backcloth of this research, it is fair to conclude that it is now commonly accepted that consumers contribute substantially to ecological and social problems - directly in the form of emissions from the consumption of goods and services and indirectly by demanding and paying for market offers which cause problematic side-effects along the value chain. Although there is still no common understanding of sustainable consumption, it is undisputed that negative impacts of dominating consumption patterns in affluent countries need to be substantially reduced to achieve sustainability.

Academic work on sustainable consumption is usually implementation-oriented. Thus, the main guiding question is directly related to the title of this special issue: "How can sustainable consumption be put into practice?" There is an ongoing debate, whether the context (e.g., the availability and attractiveness of consumption alternatives and information) or individual values, attitudes, and motives is more important for a behavioural shift towards sustainability (e.g., Jackson 2006; Thøgersen 2005; Tukker et al. 2008). Meanwhile, the understanding of the significance of context has broadened the focus on sustainable consumption beyond consumer behaviour. Especially relevant from a consumer policy perspective is governmental policy, which influences the context of consumption directly with standards, regulations, economic incentives (e.g., taxes and subsidies), and information (incl. labelling schemes). Indirectly, governmental policy additionally influences the consumption environment through its impact on other relevant actors, especially companies and non-governmental organizations (NGOs). Companies influence consumers mainly by providing more or less sustainable goods and services. In a modern market economy, the chances for a shift towards sustainable consumption depend decisively on the sustainability and attractiveness of the product supply by companies. NGOs, such as environmental or human rights organizations, are relevant stakeholders for companies and important lobby groups towards the polity. They push other actors-including the consumers - to a deeper consideration of sustainability issues. In addition, they use their credibility to facilitate sustainable consumption, e.g., via labelling schemes.

The call for papers for this special issue generated manuscripts on sustainable consumption seen from the consumer side as well as from the perspectives of various actors and actions that shape the context of consumption. After an intensive review process, ten papers were accepted, which represent most facets of consumer-policy-relevant state-ofthe-art research on sustainable consumption (Fig. 1).

Not unexpectedly for a policy journal, nearly half of the papers in this issue focus directly on policy instruments. Two papers reflect national policy approaches to sustainable consumption and two propose tools to evaluate these policies.

In her paper on pioneering national programmes for sustainable consumption and production (SCP), Annukka Berg (2011) analyses the different approaches in Finland, Sweden, and UK. By combining Princen's (2003) differentiation of principles for sustainability with characteristics of weak and strong sustainability, she develops a framework for analysing SCP policy. An application of this framework shows that all three analysed countries follow the principle of deliberation, but while Finland and UK are primarily efficiency-oriented, Sweden focuses also 


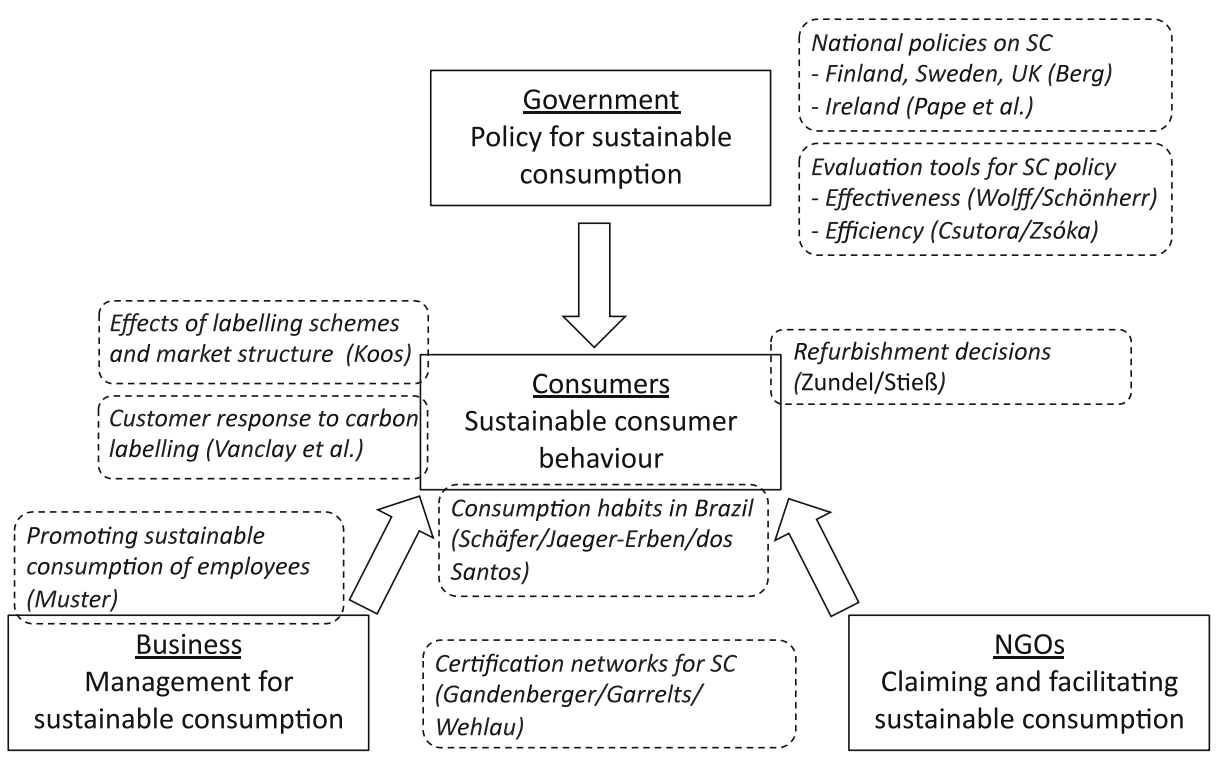

Fig. 1 Topics covered by the special issue

on sufficiency. Annukka Berg points out that the three SCP programmes do not provide clear roadmaps towards sustainability, but rather, mixed toolboxes. The fact that the tools often have to be used by various non-governmental actors can be interpreted as an attempt by governments to "outsource" responsibility for SCP.

Despite the shortcomings of their programmes, Finland, Sweden, and the UK are considered forerunners in the field of sustainable consumption. Relative to these countries, the Republic of Ireland has chosen a more reluctant approach to SCP. Nevertheless, Pape et al. (2011) picked this country to illustrate specific obstacles and approaches for consumer policy to promote sustainable consumption. They start with a characterisation and illustration of the three basic political approaches, regulation, economic incentives, and communication/information. Using this typology, they compare the situation in Ireland with examples of good practices from Europe. They show that sustainable consumption policy in Ireland was, for a long time, not very prominent and has been mainly driven by international initiatives. Deficits in this field are to a large extent due to the weakness of regional governments that have the responsibility for implementing SCP policy in Ireland, but not sufficient power. The authors recommend that Ireland learns more from international examples and that it should put more emphasis on the involvement of the people instead of following top-down approaches.

Wolff and Schönherr (2011) present a tool which would allow a systematic assessment of such an improved sustainable consumption policy. Based on a review of literature on policy evaluation, they propose a framework for evaluating and explaining effects of sustainable consumption instruments. The framework is presented in the form of a step-bystep guideline with nine steps in total. The effects include changes in consumption patterns ("outcomes"), resulting changes in the state of the environment, society, and/or economy ("impacts") and side-effects. To enable users of the tool to explain observed effects, the authors present theory-based hypotheses on drivers and barriers for the effectiveness of sustainable consumption instruments. 
While Wolff and Schönherr are concerned with the effectiveness of instruments (i.e., the degree of target achievement), Csutora and Zsóka (2011) present an approach to increase the efficiency of consumer policy. Inspired by Hockerts and Wüstenhagen (2010), they start with the proposition that "green positioning" is only likely to be successful when targeting environmentally conscious consumers while "efficiency-focused positioning," which concentrates on efficiency gains of a greener product or solution, can reach every consumer, regardless of environmental awareness. They use the example of greenhouse gas (GHG)related consumer policy to show how the application of marginal cost curves can help to select the most efficient instruments. Illustrated with case studies from Hungary, they indicate that the costs of GHG mitigation (in tons of $\mathrm{CO}_{2}$ ) are lowest for light bulb substitution and much lower for, e.g., house refurbishment (insulation, replacement of windows) than for, e.g., photovoltaic cells. The authors recommend allocating the policy budget accordingly.

The focus on house refurbishment and energy use at home is a very relevant example in the context of sustainability since housing is the field of consumption with the biggest impact on climate change. Thus, it is appropriate that this special issue comprises a second paper on energy-efficient refurbishment - especially since it presents a different and complementary perspective to that of Csutora and Zsóka. By focussing on the individual consumer decision, the Zundel and Stieß (2011) study reveals that profitability is not the only and not always the most important determinant of private homeowners' decision for or against energy-efficient refurbishment. Based on a survey among 1,008 homeowners in Germany, they found that not only cost savings and increase of the house's value are given as reasons for an energy-efficient refurbishment but also the satisfaction of needs for comfort, convenience, and belonging as well as altruistic reasons (like making a contribution to climate protection).

While economic incentives and regulations are dominating policy instruments to stimulate energy-efficient refurbishment of private homes, they play a less significant role in other fields of consumption. Especially with regards to food choice, eco- and social labelling are widespread consumer information instruments to promote and enable sustainable consumption. Three papers in this special issue focus on labelling. Gandenberger et al. (2011) analyse certification networks behind prominent product labels. They chose the Fairtrade Labelling Organisation (FLO) and the Forest Stewardship Council (FSC) as two examples in which different non-governmental and business actors work together to establish a credible certification and labelling scheme. If certification networks are successful, they contribute to more sustainable production and consumption patterns, and they do so through the market instead of through direct governmental intervention. Based on governance theory, the authors discuss the governance mechanisms and the many positive structural-material (e.g., altered market and incentive structures) and regulative-normative effects (e.g., altered institutions), but also the limitations of FLO and FSC.

In his study on determinants for the success of environmental labelling, Sebastian Koos (2011) uses a comparative framework to analyse the impact of organizational varieties of environmental labelling and market supply characteristics on the purchase of environmental labelled goods. For 18 European countries, he consolidated data on state involvement in dominating labelling schemes for organic food and consumer durables, label fragmentation, the number of labelled goods, and the structure of the retail sector. These determinants were used to explain differences in individual purchases of environmental labelled goods, reported in the Eurobarometer survey. By means of random intercept regression models, Koos find that the number of labelled goods and the concentration of the retail sector, as the only ones among the included variables, have a robust positive effect on the purchase of environmental labelled goods. 
Jerome K. Vanclay et al. (2011) analysed responses of Australian consumers to carbon labelling of groceries. They labelled 37 products, based on the carbon emissions embodied in them, with green (below average), yellow (near average), and black (above average) footprints. Over a 3-month period ( 1 month before and 2 months after the labelling), the sale of 2,890 labelled products was recorded. The authors found that negative (black) labelling had slightly more impact than positive (green) labelling (6\% decrease compared with $4 \%$ increase) and that the effect did not increase after the first month. In cases where carbon and price signals coincide (i.e., where green-labelled products were the cheapest alternative), the "green" buying rose continuously up to $20 \%$. Based on these findings, Vanclay et al. recommend a combination of carbon labelling and economic incentives (e.g., via an eco-tax reform).

Labelling is a typical example of how companies may contribute to consumer policy aims by addressing sustainability-oriented customers with offers which have environmental and/or social advantages. However, supplying their customers is not the only way companies can foster sustainable consumption. They may also do so via their employees. As Viola Muster (2011) shows, employees are always private consumers too, and companies have special chances and good reasons to promote their employees' sustainable consumption. Based on theories of social learning and socialization, she argues that the workplace is well suited for learning sustainable behaviour, which can be transferred to private consumption. Companies can benefit from increased job satisfaction, retention, and reputation, especially if they involve the employees themselves early in the process. Otherwise, they might face employees' reactance against what they may experience as an infringement on their private life. Consumer policy can play a key role in diffusing this approach among companies.

Despite the global claim of sustainable development, all papers mentioned so far have focussed on consumption in affluent societies, especially in Europe. The last paper of the special issue broadens this perspective. Schäfer et al. (2011) present an explorative survey of consumption habits and orientations in Southern Brazil. Based on interviews with 296 low- and middle-income respondents, they reveal the advanced diffusion of resourceintensive consumer goods among Brazilian consumers and their orientation towards an affluent lifestyle. As a basis for developing target-group-specific products and services as well as differentiated sustainability communication strategies, the authors use cluster analysis to identify five different consumer types (the Home-Centred Traditionals, the Indifferent, the Up-to-date Privileged, and the Wannabe Materialists). In general, the paper dampens any optimism that "leapfrogging" from poverty to sustainable consumption is likely to happen in emerging countries. At least, this is hardly feasible as long as people in the more developed world, who often function as role models for consumers in emerging countries, satisfy their needs in unsustainable ways.

Together, the articles in this special issue deliver important contributions to answer the questions of necessary change. They focus on developing solutions for a sustainable future, and they do so with a strong sense of realism, without neglecting goal conflicts, rebound effects, or other obstacles along the way. Hence, this special issue is a significant contribution to the development of a consumer policy which promotes sustainable consumption. On the other hand, it is obvious when reading this and other recently published special issues that there is still an urgent need for more policy-oriented and policy-relevant research on sustainable consumption. In order to stimulate and facilitate research in this area, the Journal of Consumer Policy has decided to reserve space for a second special issue, titled "From Knowledge to Action-New Paths towards Sustainable Consumption," to be published in 2012. We hope that other journals will also make an extra effort, via special issues or in other ways, to stimulate this urgently needed area of research in the coming years. 
Acknowledgements The special issue editors are very grateful to more than 30 anonymous reviewers. This special issue would not have been possible without their help and expertise.

\section{References}

Berg, A. (2011). Not roadmaps but toolboxes: Analysing pioneering national programmes for sustainable consumption and production. Journal of Consumer Policy doi:10.1007/s10603-010-9129-2

Csutora, M., \& Zsóka, A. (2011). Maximizing the efficiency of greenhouse gas related consumer policy. Journal of Consumer Policy doi:10.1007/s10603-010-9147-0

EEA. (2005). Household consumption and the environment. Copenhagen: European Environment Agency.

Gandenberger, C., Garrelts, H. \& Wehlau, D. (2011). Assessing the effects of certification networks on sustainable production and consumption: The cases of FLO and FSC Journal of Consumer Policy doi:10.1007/s10603-011-9155-8

Gardner, G., Assadourian, E., \& Sarin, R. (2004). The state of consumption today. In B. Halweil \& L. Mastny (Eds.), State of the world 2004 (pp. 3-21). New York: W.W. Norton/Worldwatch Institute.

Hansen, U., \& Schrader, U. (1997). A modern model of consumption for a sustainable society. Journal of Consumer Policy, 20, 443-468.

Heiskanen, E., \& Pantzar, M. (1997). Toward sustainable consumption: Two new perspectives. Journal of Consumer Policy, 20, 409-442.

Hockerts, K., \& Wüstenhagen, R. (2010). Greening goliaths versus emerging Davids_-Theorizing about the role of incumbents and new entrants in sustainable entrepreneurship. Journal of Business Venturing, 25 , $481-492$.

Jackson, T. (2006). Challenges for sustainable consumption policy. In T. Jackson (Ed.), The Earthscan reader in sustainable consumption (pp. 109-126). London: Earthscan.

Koos, S. (2011). Varieties of environmental labelling, market structures and sustainable consumption across Europe: A comparative analysis of organizational and market supply determinants of environmental labelled goods. Journal of Consumer Policy doi:10.1007/s10603-010-9153-2

Micheletti, M., \& Follesdal, A. (2007). Shopping for human rights. An introduction to the special issue. Journal of Consumer Policy, 30, 167-175.

Muster, V. (2011). Companies promoting sustainable consumption of employees. Journal of Consumer Policy doi:10.1007/s10603-010-9143-4

Pape, J., Rau, H., Fahy, F., \& Davies, A. (2011). Developing policies and instruments for sustainable household consumption: Irish experiences and futures. Journal of Consumer Policy doi:10.1007/s10603-010-9151-4

Princen, T. (2003). Principles for sustainability: From cooperation and efficiency to sufficiency. Global Environmental Politics, 3(1), 33-50.

Schäfer, M., Jaeger-Erben, M., \& dos Santos, A. (2011). Leapfrogging to sustainable consumption? An explorative survey of consumption habits and -orientations in Southern Brazil. Journal of Consumer Policy doi:10.1007/s10603-010-9150-5

Spaargaren, G. (2003). Sustainable consumption-A theoretical and environmental policy perspective. Society and Natural Resources, 16, 687-701.

Spangenberg, J. H., \& Lorek, S. (2002). Environmentally sustainable household consumption: From aggregate environmental pressures to priority fields of action. Ecological Economics, 43(2-3), 127-140.

Thøgersen, J. (2005). How may consumer policy empower consumers for sustainable lifestyles. Journal of Consumer Policy, 18, 143-178.

Tukker, A., Emmert, S., Charter, M., Vezzoli, Sto, E., Anderson, M. M., et al. (2008). Fostering change to sustainable consumption and production: An evidence based views. Journal of Cleaner Production, 16, $1218-1225$.

Vanclay, J. K., Shortiss, J., Aulsebrook, S., Gillespie, A. M., Howell, B. C., Johanni, R., et al. (2011). Customer response to carbon labelling of groceries. Journal of Consumer Policy doi:10.1007/s10603-010-9140-7

Wolff, F., \& Schönherr, N. (2011). Putting sustainable consumption into practice: The impact evaluation of sustainable consumption policy instruments. Journal of Consumer Policy doi:10.1007/s10603-0109152-3

Zundel, S., \& Stieß, I. (2011). Beyond profitability of energy saving measures: Energy efficient refurbishment. Journal of Consumer Policy doi:10.1007/s10603-011-9156-7 